\title{
PHONETIC ASPECT OF YOUNG PEOPLE'S SPEECH PORTRAIT (EXEMPLIFIED BY SPEECH OF MILITARY INSTITUTE CADETS)
}

\author{
Olga P. Fesenko \\ Omsk Tank-Automotive Engineering Institute, Omsk, Russia
}

\begin{abstract}
The paper deals with the reconstruction of speech portrait which is defined as a part of verbal personality, verbalized in the communication process. The purpose of our research is to analyze linguistic features of the cadet's speech portrait, which are implemented at the phonetic level. The subject of the research is the verbal picture of the cadets of a military institute. The object is its phonetic aspect. The research material is represented with dictaphone recordings of educational discourse ( 240 hours long). The recordings were made at the lessons of different academics for the first, the second and the third-year cadets (disciplines - Russian Language and Culture of Speech, Military History, Law). 512 cadets took part in the research. The main method is the method of scientific description with the use of the following techniques: observation, continuous sampling, classification, systemization, interpretation and statistical data processing.

The cadets' speech portrait is balanced enough, but it requires certain correction as for accentological and articulatory standards. The cadets made about 70 mistakes, which are typical for the young people's speech. When modeling the cadets' speech portrait, the special attention should be given to speech delivery. Its development is one of the factors for successful communication in the military professional sphere.

The research results can be the foundation for reconsideration of the content of educational standards in military specialties. The given phonetic aspect of the young people's speech portrait enlarges existing in linguodidactics concepts about the analyzed phenomenon and contributes to the development of linguodidactics and sociolinguistics. The phonetic features of the cadets' speech portrait are shared by all the young people.

Key words: speech portrait, cadet's speech portrait, phonetic aspect of speech portrait, orthoepic mistake, accentological mistake, educational discourse.

Citation. Fesenko O.P. Phonetic Aspect of Young People's Speech Portrait (Exemplified by Speech of Military Institute Cadets). Vestnik Volgogradskogo gosudarstvennogo universiteta. Seriya 2, Yazykoznanie [Science Journal of Volgograd State University. Linguistics], 2018, vol. 17, no. 3, pp. 91-98. (in Russian). DOI: https:// doi.org/10.15688/jvolsu2.2018.3.9
\end{abstract}

УДК 811.161.1’355

Дата поступления статьи: 04.05.2018

ББК $81.411 .2-1$

Дата принятия статьи: 05.06.2018

\section{ФОНЕТИЧЕСКАЯ СОСТАВЛЯЮЩАЯ РЕЧЕВОГО ПОРТРЕТА СОВРЕМЕННОЙ МОЛОДЕЖИ (НА ПРИМЕРЕ РЕЧИ КУРСАНТОВ ВОЕННОГО ВУЗА)}

\footnotetext{
Ольга Петровна Фесенко

Омский автобронетанковый инженерный институт, г. Омск, Россия

Аннотация. Статья посвящена реконструкции речевого портрета, который определяется как составляющая речевой личности, вербализуемая в процессе коммуникации. Цель исследования - проанализировать лингвистические черты речевого портрета курсанта, реализующиеся на фонетическом уровне. Материал исследования составили диктофонные записи учебного дискурса (240 часов).

Установлено, что речевой портрет курсантов гармоничен, хотя требуется незначительная корректировка с точки зрения соблюдения акцентологической и произносительной норм. В речи курсантов выявлены
} 
ошибки, типичные для речи современной молодежи. Определено, что особую роль при формировании речевого портрета курсантов играют артикуляция и дикция, их развитие является одним из факторов успешной коммуникации в военной профессиональной сфере.

Полученные в результате исследования данные могут стать основой для пересмотра содержания образовательных стандартов по военным специальностям, корректировки содержания лингвистических дисциплин не только в военных учебных заведениях, но и в вузах страны в целом. Описанная фонетическая составляющая речевого портрета курсантов как представителей современной молодежи дополняет имеющиеся сведения об анализируемом феномене, а проведенное исследование вносит вклад в развитие лингводидактики и социолингвистики.

Ключевые слова: речевой портрет, речевой портрет курсанта, фонетическая составляющая речевого портрета, орфоэпическая ошибка, акцентологическая ошибка, учебный дискурс.

Цитирование. Фесенко О. П. Фонетическая составляющая речевого портрета современной молодежи (на примере речи курсантов военного вуза) // Вестник Волгоградского государственного университета. Серия 2, Языкознание. - 2018. - Т. 17, № 3. - C. 91-98. - DOI: https://doi.org/10.15688/jvolsu2.2018.3.9

\section{Введение}

Одним из актуальных направлений современной лингводидактики является исследование речевого портрета обучающегося. Зная особенности речевого портрета студентов, педагог может скорректировать основные направления своей деятельности, подходы к отбору и подаче учебного материала, повысить качество освоения языковой дисциплины. В вузе учет специфики речи студентов (или курсантов) не менее важен, чем в школе. Он обусловливает темпы и прочность овладения разными учебными предметами, а также языком профессии.

Цель нашего исследования - выявить собственно лингвистические особенности речевого портрета курсанта, реализующиеся на фонетическом уровне.

Материалом для изучения послужили диктофонные записи (240 часов), которые были сделаны на занятиях по различным дисциплинам 1, 2 и 3-го курсов («Русский язык и культура речи», «Военная история», «Правоведение»). В исследовании приняли участие 512 обучающихся. Выбор учебных дисциплин был обусловлен их гуманитарной направленностью и возможностью для обучающихся вступать в процесс коммуникации или оформлять монолог в ходе занятия. Выбор курсантов первых трех лет обучения продиктован тем, что они являются активно формирующимися языковыми личностями. Их речевой портрет в значительной степени динамичен и может поддаваться корректировке. Старшекурсники, от исследования речевого портрета которых мы отказались изначально, - это состоявшиеся военнослужащие, у которых закончился срок срочной службы и оформлена служба по контракту. Следовательно, их языковая личность и речевой портрет как специалистов уже сформированы и обладают рядом черт, которые во многом определяются спецификой профессиональной коммуникации.

\section{Теоретические основы исследования}

Описание речевого портрета (далее- РП) связано, прежде всего, с его фонетической характеристикой. Как отмечают исследователи, первые описания звуковой составляющей РП появились еще в 60-е годы XX столетия в работах Е.Д. Поливанова, создавшего фонетические портреты известных писателей, ученых и политиков (см. об этом: [Крысин, 2004]). Подробное описание русского речевого портрета в фонетическом аспекте осуществили М.В. Китайгородская и Н.Н. Розанова [1995]. Наибольший интерес исследователей речевое портретирование вызвало в 80-90-е годы XX века. Важнейшим положением, сформулированным в рамках лингвистической науки того времени, стало утверждение о том, что в речевом портрете человека отражается его принадлежность к социальным общностям (подробно см.: [Бойко, 2008]). Если человек одновременно входит в несколько профессиональных структур, то специфическими чертами его речевого портрета становятся полиглоссность и диглоссия (в трактовке Л.П. Крысина).

Ученые многократно осуществляли обзор толкований термина «речевой портрет» 
(см., например: [Павлычева, 2016]). Это понятие рассматривается учеными с двух позиций:

1. РП является основной составляющей языковой личности, воплощающей ее языковые характеристики, реализующиеся в коммуникации (письменной или устной). При этом под РП может пониматься как представленная в речи языковая личность [Солодянкина, Хвостова, 2012, с. 156] в самом широком смысле этого термина, так и различные еe речевые воплощения с учетом конкретных социальных характеристик [Леорда, 2006, с. 6].

2. Языковая личность отождествляется с РП, поскольку одно без другого не существует и говорить о языковой личности без учета особенностей ее коммуникации нельзя [Барашева, 2014; Иссерс, 2002].

Для нас наиболее оптимальным является первый вариант трактовки с тем лишь дополнением, что РП - это часть речевой личности (языковой личности в узком понимании термина), вербализуемая в процессе коммуникации.

Интерес современной лингвистической науки к фонетическим особенностям речи языковой личности связан во многом с тем, что «фонетические характеристики речи индивидуума являются отражением личностных черт, заключенных в его РП и включающих в себя возрастные, гендерные, психологические, социальные, этнокультурные и лингвистические особенности человека» [Бабушкина, 2012, с. 9]. Фонетические признаки, по мнению ученых, чрезвычайно показательны для анализа речевого портрета (см., например: [Мороз, 2011, c. 197]). Важно и то, что проконтролировать реализацию навыков произношения и использования интонации носителю языка достаточно проблематично, поскольку они абсолютно автоматизированы. Жесткий самоконтроль этой сферы общения максимально затруднил бы его, сделал крайне неудобным и непродуктивным. В связи с этим анализ фонетической стороны РП позволяет получить наиболее объективные сведения о его специфических чертах.

Исследователи при анализе фонетической составляющей РП обучающихся обращают внимание на следующие особенности:

1. Произнесение звуков (ослабление артикуляции, нечеткая дикция, стяжение гласных и т. д.). Речь идет об искажении фонетическо- го облика слова. Сюда же можно отнести появление лишнего звука или исчезновение необходимого звукового элемента в слове, связанные с нарушением орфоэпической нормы.

2. Постановка ударения в словах (то есть особенности соблюдения акцентологической нормы «с указанием вариантов и сравнительной частотности их употребления в живой устной речи» [Загоровская, 2013, с. 175]).

\section{Методы исследования}

Теоретико-методологическую основу исследования составили труды, посвященные разработке теории РП в коммуникативной лингвистике, лингводидактике и социолингвистике (Б.Л. Бойко, О.С. Иссерс, С.В. Леорда, О.В. Загоровская, Л.П. Крысин, Н.В. Солодянкина и др.) и фонетической составляющей РП (Е.А. Бабушкина, М.В. Китайгородская, Н.Ю. Мороз).

Нами были использованы следующие методы и приемы:

- анализ, синтез и обобщение (при изучении научной литературы, документов и образовательных стандартов высшей школы);

- дескриптивный и сопоставительный методы (при составлении текста научной работы и анализе полученных результатов исследования);

- метод слухового анализа;

- прием количественных подсчетов (при систематизации фонетических ошибок);

- метод сплошной выборки (при анализе дискурса и языкового материала). Мы не анализировали те фонетические параметры, которые связаны с диалектными особенностями речи, поскольку в институте обучаются курсанты из самых разных регионов России (от Калининграда до Владивостока).

\section{Результаты и обсуждение}

В речи испытуемых были выявлены следующие нарушения орфоэпической нормы:

- Нечеткое произнесение конца слова с последующей утратой последних согласных звуков в слове: выно́сливо [c'] вместо выно́сливо [c'm']; то́ е [c'] вместо тó e[c'm']; $n y$ [c'] вместо $n y\left[c^{\prime} m\right.$ ']; жи[c'] вместо жи[з'н']. 
- Выпадение звуков или слогов (диереза): ч[э' ] ство вместо че[лАв'е́ч']ество;

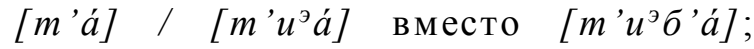
$m$ [^á]рищ вместо $m$ [^ва́]puщ; здра́[c'b]me вместо здра́[ствуй]те; ли́[чь] состав вместо ли́чный состав; во́се [м'] сят вместо

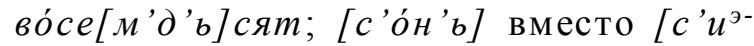
во́дн'b]; ни[ч'ó] вместо ни [ч'u’вó]; де́[y]-

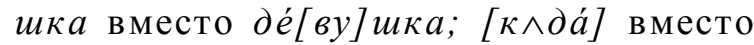
ко[гда́]; бý[b]m вместо бу́[d 'b]m; [c'ó] равно вместо [фc'ó] равно. Вариант [щ̧á]c вместо $\left[c^{\prime} u^{3} i\right]$ чác, функционирующий в речи курсантов, мы отнесли к ошибочным, поскольку он был использован на учебном занятии в рамках официально-делового и научного стилей, что недопустимо, поскольку вариант [щ̧á]c хотя и находится в пределах литературной нормы, но в словаре имеет помету разг. (ОСРЯ, c. 524). В Большом орфоэпическом словаре (БОС) данное слово не зафиксировано.

- Замена согласных звуков: физи́[щ']ески вместо физи́[ч']ески; физи́[щ']еской вместо физи́[ч']еской; ди[л']екти́ва вместо ди[p']екти́ва. Последний вариант вызван дистантной регрессивной диссимиляцией по способу образования и является ошибкой, рассматривающейся в стилистике как грубое просторечие.

- Несоблюдение норм произношения твердых и мягких согласных в заимствованных словах. В некоторых заимствованных словах с приставками де- или дез- наблюдается общая тенденция к смягчению согласного звука $\partial$, однако при этом встречаются и колебания в произношении твердого или мягкого $\partial$ (подробно см.: [Розенталь, Джанджакова, Кабанова, 1999]). Речь курсантов в этом отношении не является исключением, отражая названную тенденцию и в то же время включая описанные варианты, каждый из которых согласно словарям имеет право на существование в рамках литературного языка: деп [p]е́ссия и деп[p']е́ссия (ОСРЯ, с. 18); стра[m]е́zия и стра[m']е́zия (ОСРЯ, с. 550); аг[р]есси́вно и аг[p']есси́вной, аг[р]е́ссия и аг[p']е́ссия (ОСРЯ, с. 21). Однако в последнем издании Большого орфоэпического словаря варианты произношения твердых согласных отмечены как «неправильные» (БОС, c. 164), поэтому именно твердые варианты рассматриваются нами как ошибочные.
- Утрата мягкости согласного: неда́в[ну]ю вместо неда́в $\left[\mu^{\prime} y\right] ю$.

- Утрата твердости согласного звука (ассимиляция по мягкости): на компьюб[m']ере вместо на компьюб[m]ере; патриоти́[з']м вместо патриоти́[з]м.

- Усиленная редукция гласных (стяжение гласных): фoom [^]nnapám вместо фom $[\mathrm{b} \wedge$ ]nnapám.

- Появление лишних звуков или слогов в слове (эпентеза): произведенено́ вместо произведено́.

В речи курсантов отмечено функционирование вариантов, связанных с заменой гласных звуков в слове: сосредот [á] чивать и сосредот[ó]чивать. Первый был использован курсантами 4 раза, второй (с ударением на $o ́$ ) зафиксирован однократно, однако оба варианта рассматриваются как равноправные в современных лексикографических источниках (БОС, с. 803; ОСРЯ, с. 550).

Всего зафиксированы 95 отклонений от произносительной нормы русского литературного языка. Большинство из них единичны, их нельзя считать типичными для речи курсантов в целом. При этом имеются примеры трехкратного ([c'ó] равно вместо

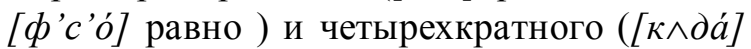
вместо [к^гда́]) повтора ошибок в речи разных курсантов.

Наиболее частотными среди орфоэпических нарушений можно считать выпадение звуков и слогов, а также нечеткое произнесение конца слова. Эти ошибки вызваны ослабленной артикуляцией и нечеткой дикцией говорящего, что представляется нам неприемлемым в военной сфере, поскольку от дикции командира во многом зависит четкость выполнения поставленной перед подчиненным задачи. Хотя общее количество подобных ошибок нельзя считать предельным (оно невелико - 58), требуется некоторая корректировка речи курсантов, поскольку артикуляция и дикция оказываются профессионально значимыми.

Обнаруженные нами отклонения стилистически можно охарактеризовать как просторечные, поскольку, как отмечает Л.П. Крысин, для современного просторечия характерны: 1) стяжение гласных; 2) диссимиляция согласных по месту и способу образования; 
3) отсечение части консонантных сочетаний в финалях слов; 4) упрощение слоговой структуры слова и др. [Крысин, 2004, с. 134-138]. Последний и наиболее частотный тип ошибки характерен не только для малограмотного населения, но и для современных школьников (см. об этом: [Мамаева, 2007, с. 10-11]).

Речь курсантов соответствует младшей орфоэпической норме с нейтральным стилем произношения, что вполне закономерно и объяснимо, поскольку для старшей нормы, как отмечается в научной литературе, «характерно произношение було[шн]ая, мяг[къй], [з'в']ерь. Младшая произносительная норма, наблюдаемая в речи молодежи, владеющей литературным языком, допускает произношение було[чн]ая, мяг[к'ий]. Нормы высокого стиля произношения < ...> допускают, например, произношение безударного звука [о] в заимствованных словах: $n[o] э m, ~ c[o] н е т$, н[о]ктюрн. В нейтральном стиле эти и подобные слова произносятся по общему правилу замены безударного звука [о] звуком [^]: $n[\wedge] э m, c[\wedge]$ нет, н[^]ктюрн» [Касаткин, Клобуков, Лекант, 2005, с. 282].

Несмотря на наличие грубейших нарушений нормы русского литературного языка, следует отметить, что подобных ненормативных вариантов в речи курсантов немного. Они свидетельствуют о некоторой недостаточности знаний по русскому языку и вполне преодолимы в процессе освоения вузовского курса «Русский язык и культура речи».

При анализе нарушений акцентологической нормы нами были зафиксированы 36 ошибочных употреблений. Это изменения места постановки ударения:

- в глагольных формах: человечество не поняло́, предло́жил решение проблемы, ро́стят (вариант отклонения от акцентологической нормы является еще и грамматической ошибкой), обле́гчила;

- в форме именительного падежа имени существительного: ходата́йство, обеспече́ние, жизнеобеспече́ния, сосредоточе́ние;

- в формах множественного числа имен существительных: в глубина́х сознания, двигателя́ (мн.ч., И.п.), средства́ми, средства́, местностя́х;

- в прилагательных и причастиях: брони́рованные машины, речь была воспри́нята;
- в названиях: на реке О́ми, Армия Верма́хта.

Наряду с приведенными ошибками в речи курсантов функционируют устаревающие (согласно данным ОСРЯ и БОС) варианты нуждаться в де́ньгах, отномение к де́ньгам (по три употребления каждого) одновременно с таким же количеством современных примеров (думать о деньга́х, помеманы на деньга́х). Слово до́говор с ударением на первом слоге, которое допустимо (БОС, с. 177), встретилось лишь единожды, в то время как вариант догово́р зафиксирован 17 раз.

Наиболее типичными можно считать ошибки в словах ходата́йство (6 ошибочных употреблений) и обеспече́ние (8 ошибочных употреблений). В научной литературе отмечается, что вариант обеспече́ние следует квалифицировать как знак принадлежности слова к социально-групповому диалекту военных [Бойко, 2008, с. 119]. Мы не можем с этим согласиться, поскольку в настоящее время это одна из типичных ошибок современного поколения. Неверное ударение в этом слове делает большое количество россиян вне зависимости от профессии. Например, на интернет-форумах вопрос о постановке ударения обеспече́ние или обеспе́чение обсуждается довольно часто. Носители языка возмущаются, обнаруживая, что ставят ударение в слове неверно; уверяют, что в словарях опечатка; призывают изменить правило ${ }^{1}$. В связи с этим относить данную ошибку к особенностям социально-группового диалекта военных нельзя. Отметим также, что частотность указанного нарушения уже приводит к появлению варианта ударения (пока только в РОС).

\section{Выводы}

В результате проведенного анализа обнаружено, что фонетическая составляющая РП курсантов военного вуза характеризуется рядом черт как типичных для портрета современной молодежи, так и отличных от него.

В речи курсантов зафиксированы случаи нарушения орфоэпической нормы (всего 95): нечеткое произношение конца слова с дальнейшей утратой последних согласных звуков; выпадение звуков и слогов; замена согласных зву- 
ков; утрата мягкости согласного звука как в исконно русских, так и в заимствованных словах; утрата твердости согласного звука; усиление редукции гласных; появление лишних звуков и слогов. Наиболее частотны нарушения, связанные с нечетким произношением конца слова и с выпадением слогов и звуков (всего 58). Этот тип ошибок может оказать влияние на результативность будущей профессиональной деятельности курсантов, поскольку от четкости артикуляции часто зависит качество постановки задач в армии. В целом речь курсантов соответствует младшей орфоэпической норме.

Кроме того, в исследуемом материале отмечены нарушения акцентологической нормы (36 случаев). Это изменения мест постановки ударения в глагольных формах, в форме именительного падежа имени существительного, в форме множественного числа существительного, в различных формах прилагательных и причастий, в названиях.

Большинство отклонений от произносительной нормы квалифицируются как просторечные.

Таким образом, РП курсантов в аспекте его орфоэпической составляющей гармоничен. Акцентологических и орфоэпических ошибок зафиксировано незначительное количество, поэтому нельзя говорить о том, что они типичны именно для речи курсантов, особенно если принять во внимание то, что обнаруженные нами отклонения от нормы регулярно встречаются в речи современной молодежи. Социальные параметры не влияют на особенности РП. При этом фонетическая составляющая РП курсантов военного вуза требует некоторой корректировки в отношении соблюдения акцентологической и произносительной норм русского литературного языка. В общей сложности курсанты допустили около 130 ошибок, типичных для речи современного молодого поколения. Особое внимание при формировании РП курсантов следует уделить дикции, развитие которой является одним из факторов успешной коммуникации в военной профессиональной сфере.

\section{ПРИМЕЧАНИЕ}

${ }^{1}$ См.: портал «Русский язык Бета». URL: https: //rus.stackexchange.com/questions/35162/Почемуне-обеспечЕние-а-обеспЕчение ; Интернет-форум
«Большой вопрос». URL: http://www. bolshoyvopros.ru/questions/97582-kak-pravilnogovorit-obespechenie-ili-obespechenie. html ; информационный портал Екатеринбурга. URL: http://www.ekburg.ru/news/18/45501-kakpravilno-obespechenie-ili-obespechenie/ ; ГРАМОТА.РУ - справочно-информационный портал «Русский язык для всех». URL: http://www.gramota.ru.

\section{СПИСОК ЛИТЕРАТУРЫ}

Бабушкина Е. А., 2012. Речевой портрет личности: фонетические характеристики // Вестник Бурятского государственного университета. № 11.C. 7-11.

Барашева Д. Е., 2014. Genetic aspect in psychic-social conditions of forming language ability // The Second International conference on development of psychological science in Eurasia. Vienna : «East West» Association for Advanced Studies and Higher Education GmbH. C. 3-7.

Бойко Б. Л., 2008. Принципы моделирования речевого портрета носителя социально-группового диалекта // Армия и общество. № 2. С. 114-121.

Загоровская О. В., 2013. Речевое портретирование социальной группы как задача современной лексикографии // Вестник Воронежского государственного унверситета. Серия: Лингвистика и межкультурная коммуникация. № 2. C. $174-177$.

Иссерс О. С., 2002. Проблемы создания «коммуникативного портрета»: гендерный аспект // Гендер: язык, культура, коммуникация. Доклады Второй международной конференции. М. : Московский государственный лингвистический университет, Лаборатория гендерных исследований ; Институт «Открытое общество» (Фонд Сороса). С. 172-178.

Касаткин Л. Л., Клобуков Е. В., Лекант П. А., 2005. Современный русский язык: словарь-справочник / под ред. П. А. Леканта. М. : Оникс XXI век : Мир и образование. 349 с.

Китайгородская М. В., Розанова Н. Н., 1995. Русский речевой портрет: фонохрестоматия. М. : Наука. 128 с.

Крысин Л. П., 2004. Русское слово, свое и чужое: Исследования по современному русскому языку и социолингвистике. М. : Языки славянской культуры. 888 с.

Леорда С. В., 2006. Речевой портрет современного студента : автореф. дис. ... канд. филол. наук. Саратов. $19 \mathrm{c}$.

Мамаева С. В., 2007. Речевой портрет школьника 5-7 классов : автореф. дис. ... д-ра филол. наук. Кемерово. 17 с. 
Мороз Н. Ю., 2011. К вопросу о создании «портрета» говорящего по его фонетическим характеристикам при обучении профессиональной коммуникации // Вестник Московского государственного лингвистического университета. Серия: Образование и педагогические науки. № 614. С. 196-204.

Павлычева Е. Д., 2016. Типология речевых портретов политиков в американском лингвистическом дискурсе // Евразийский союз ученых. № 31, ч. 2. С. 84-87.

Розенталь Д. Э., Джанджакова Е. В., Кабанова Н. П., 1999. Справочник по правописанию, произношению, литературному редактированию. 3-е изд., испр. М. : ЧеРо. 399 с.

Солодянкина Н. В., Хвостова А. В., 2012. Речевой портрет студента-филолога // Русская языковая личность в современном коммуникативном пространстве : Материалы Международной научной конференции. Бийск : ФГБОУ ВПО «АГАО». С. 155-159.

\section{СЛОВАРИ}

БОС - Каленчук М. Л., Касаткин Л. Л., Касаткина Р. Ф., 2012. Большой орфоэпический словарь русского языка: литературное произношение и ударение начала XXI века: норма и ее варианты / под ред. Л. Л. Касаткина. М. : АСТПресс. 1000 c.

ОСРЯ - Борунова С. Н., Воронцова В. Л., Еськова Н. А., 1989. Орфоэпический словарь русского языка: Произношение, ударение, грамматические формы / под ред. Р. И. Аванесова. М. : Рус. яз. 688 с.

POC-Русский орфографический словарь / О. Е. Иванова, В. В. Лопатин, И. В. Нечаева, Л. К. Чельцова ; под ред. В. В. Лопатина. М. : Институт русского языка им. В.В. Виноградова, 2007. 960 с.

\section{REFERENCES}

Babushkina E.A., 2012. Speech portrait: phonetic characteristics. Vestnik Buryatskogo gosudarstvennogo universiteta [Bulletin of the Buryat State University], no. 11, pp. 7-11.

Barasheva D.E., 2014. Genetic aspect in psychic-social conditions of forming language ability. The Second International conference on development of psychological science in Eurasia. Vienna, East West. pp. 3-7.

Boyko B.L., 2008. Principles of modeling the speech portrait of a social-group dialect's speaker. Armiya i obshchestvo, no. 2, pp. 114-121.
Zagorovskaya O.V., 2013. Speech portrait of a social group as a task for modern lexicography. Vestnik Voronezhskogo gosudarstvennogo unversiteta. Seriya: Lingvistika $i$ mezhkulturnaya kommunikatsiya [Proceedings of Voronezh State University. Series: Linguistics and intercultural communication], no. 2, pp. 174-177.

Issers O.S., 2002. The problems of creating communicative portrait: the gender dimension. Gender: yazyk, kultura, kommunikatsiya. Doklady Vtoroy mezhdunarodnoy konferentsii. Moscow, Izd-vo MGLU, pp. 172-178.

Kasatkin L.L., Klobukov E.V., Lekant P.A., 2005. The modern Russian language: Reference dictionary. Moscow, Oniks XXI vek; Mir i obrazovanie Publ. 349 p.

Kitaygorodskaya M.V., Rozanova N.N., 1995. Russian speech portrait: Anthology on Phonetics. Moscow, Nauka Publ. 128 p.

Krysin L.P., 2004. Russian word, native and foreign: Research on modern Russian language and sociolinguistics. Moscow, Yazyki slavyanskoy kultury Publ. $888 \mathrm{p}$.

Leorda S.V., 2006. Speech portrait of a modern student. Cand. philol. sci. abs. diss. Saratov. $19 \mathrm{p}$.

Mamaeva S.V., 2007. Speech portrait of a 5-7-grade pupil. Dr. philol. sci. abs. diss. Kemerovo. 17 p.

MorozN.Yu., 2011. The issue of creating a speaker's portrait based on their phonetic characteristics in teaching professional communication. Vestnik Moskovskogo gosudarstvennogo lingvisticheskogo universiteta. Seriya: Obrazovanie i pedagogicheskie nauki [MSLUBulletin: Education and Pedagogy], no. 614, pp. 196-204.

Pavlycheva E.D., 2016. Typology of speech portraits of politicians in American linguistic discourse. Evraziyskiy soyuz uchenykh [Eurasian Union of Scientists], no. 31, part 2, pp. 84-87.

Rozental D.E., Dzhandzhakova E.V., Kabanova N.P., 1999. Reference book on orthography, pronunciation and literary editing. Moscow, CheRo Publ. 399 p.

Solodyankina N.V., Khvostova A.V., 2012. Speech portrait of a student-philologist. Russkaya yazykovaya lichnost $v$ sovremennom kommunikativnom prostranstve: Materialy Mezhdunarodnoy nauchnoy konferentsii. Biysk, AGAO Publ., pp. 155-159.

\section{DICTIONARIES}

Kalenchuk M.L., Kasatkin L.L., Kasatkina R.F., 2012. Big orthoepic dictionary of the Russian language: literary pronunciation and stress in the beginning of the $21^{\text {st }}$ century. The norm and its variants. Moscow, AST-Press. 1000 p. 


\section{РАЗВИТИЕ И ФУНКЦИОНИРОВАНИЕ РУССКОГО ЯЗЫКА}

Borunova S.N., Vorontsova V.L., Eskova N.A., 1989. Orthoepic dictionary of the Russian language: Pronunciation, stress, grammatical forms. Moscow, Russkiy yazyk Publ. 688 p. URL: http:// www.povto.ru/pr_udar.htm (accessed 1 September 2017)
Ivanova O.E., Lopatin V.V., Nechaeva I.V., Cheltsova L.K., 2007. Russian dictionary of orthography. Moscow, Institut russkogo yazyka im. V.V. Vinogradova. 960 p. URL: https://profilib.com/chtenie/26885/ vladimir-lopatin-russkiy-orfografich eskiyslovar.php (accessed 6 September 2017)

\section{Information about the Author}

Olga P. Fesenko, Doctor of Sciences (Philology), Associate Professor, Professor of Department of Foreign and Russian Languages, Omsk Tank-Automotive Engineering Institute, Lermontova St., 4-12, 644024 Omsk, Russia, Olga.Fesenko2015@yandex.ru, https://orcid.org/0000-0002-2373-1880

\section{Информация об авторе}

Ольга Петровна Фесенко, доктор филологических наук, доцент, профессор кафедры иностранных и русского языков, Омский автобронетанковый инженерный институт, ул. Лермонтова, 4-12, 644024 г. Омск, Россия, Olga.Fesenko2015@yandex.ru, https://orcid.org/0000-0002-2373-1880 